\title{
The Innovative Design of Modern Residential Building
}

\author{
Zhuqiang Xiao ${ }^{1}$ and Xingyu Wang ${ }^{2}$ \\ ${ }^{1}$ Institute of Art \& Design, Nanchang Hangkong University, Nanchang, China \\ ${ }^{2}$ Institute of Art \& Design, Wuhan University of Technology, Wuhan, China
}

\begin{abstract}
The contemporary urban design innovative residential buildings were fully explored, from the relevant factors specific innovation, innovative thinking and innovative methods, several aspects of the innovative design of residential buildings for a detailed elaboration, residential building design innovation theory and innovative practice provide a reference.
\end{abstract}

Keywords-component; residential building; building design; innovation

\section{INTRODUCTION}

The rapid development of modern society, the rapid expansion of urban expansion, continue to produce a large number of residential buildings, and these homes are designed to express the latest design news and trends, reflecting the latest scientific and technological achievements of the building, these are the designers of the building continues Innovative design results. Architects tend to express the residential function and personality through the latest ideas and creativity, leading to a rich semantic and content of residential buildings is created. Overall, the building's architectural design is undoubtedly the creation, creation of particularly innovative because of its architectural creation is a manifestation of the architect-designed buildings have new ideas, new ideas, and to promote architects use architectural form, technique, language and create out with new features, new image, new personality building [1]. It should be noted that the building of innovative design not only a single finger architectural form innovation, but also include aspects of innovative thinking consciousness and technical methods and so on. These rich innovative elements for our residential construction innovation provides a variety of possible directions, thus we can see that the innovative design of modern housing needs analysis and reflection from multiple angles.

\section{FACTORS INNOVATIVE DESIGN OF RESIDENTIAL BUILDINGS}

There are many factors affect innovation in the specific design of residential buildings, if from the nature of residential buildings can be carried out to explore the following aspects.

\section{A. Residential Buildings Design Goals}

Residential building basic aim is to meet people's material needs of life, to achieve the basic functions of living. But with the development of society and economy, while housing has been given additional functionality, its function is more deepseated cultural values of a certain form of this building and to create economic benefits. The creation of economic value of this goal is an important component of contemporary residential building design, which is the inevitable result of social and economic development, what really makes the residential building from a simple article has a use value into a function with a hedge against inflation, can produce good economic returns of product so that residential construction has become an important part of the whole social economy. Therefore, based on economic promotion of residential buildings and more comfortable living requirements as the goal, modern residential building design more advanced elements into the building, emphasizing the overall architecture of comfort and versatility, creating reflect modern architecture space environment, make the building more functions and investment value.

\section{B. Design Features of Residential Building}

Residential architectural design always express new ideas and practices, techniques and materials, and the development of technology and its expression pattern changes will occur naturally. First of all, areas of modern residential building design has been very involved in a wide range, including theoretical material, environment, ecology and other natural sciences knowledge and economics, history, aesthetics and other social sciences, this complex theoretical construction of residential buildings having more profound connotation, which makes modern residential building is with visual effects and psychological implications of high-end products. Secondly, a modern residential building design process is a complex combination of factors in the latest thinking, is new construction technology to create a complex form of the complex, which also makes each member modern residential building denser relationship exists, so the specific design handle organizational relationships during each member, so that the final form of the residential building more stable structure, a stable support a variety of functions.

\section{Innovative Impetus Residential Building Design}

Residential building has been designed to constantly move forward and change, holding a new vitality, is subject to a series of factors affecting the social development process produced, these elements become residential architectural design and innovative impetus. The first is to enhance people's thinking, and to a higher housing requirements, not only to meet the basic requirements of living functions while requiring residential presence in the form of art, to meet higher user psychological enjoyment and spiritual pursuit. Followed by the modern environmental concepts and closer to the natural 
ecological state of life to promote residential building design evolution occurs, to form a more rational morphology to adapt to the natural environment. Once again, the architect of innovation requires subjective, modern architectural design architect at the time, often on their own, higher design requirements, to provide more high-quality architectural design as the purpose, and constantly self-improvement, selfcriticism, self-correction for residential buildings to provide new solutions, giving new meaning to the residential building.

\section{INNOVATIVE THINKING OF RESIDENTIAL ARCHITECTURAL DESIGN}

Innovative thinking requires architectural design to break the routine problem-solving approach, build something new logical relationship to the design issues new solutions. It is logical thinking and thinking in images combining creative method of combining realism and romanticism, which is built on a profound analysis of the design conditions and prerequisites properly understood, to miss the point and substance, with a rich imagination and inspired obtained in the pondering, the use of architectural language peculiar way of expression and composition skills, creating a profound ideological and artistic excellence in perfect unity of architectural image [2]. Residential building design due to its popularity for the group, in the face of the functional requirements of different groups, so that it is always in the forefront of design thinking innovation.

\section{A. A Single Three-Dimensional Way of Thinking and Complex Combination of Plane}

Objective things in terms of the macro is an organic whole, it has space and multi-level multi-dimensional plane. Residential building space and plane forms a complex relationship network, different attributes of various elements intertwined, expressing the inner and outer elements form residential buildings. In order to resolve these complex architectural hierarchy, you must request a new mode of thinking, ways of thinking and therefore proposed a single three-dimensional thinking and thinking of combining complex plane to resolve the various properties of residential buildings, the key point is the ability of each residential building various kinds of spatial relations and constitute flat space overall, comprehensive and integrated consideration, complete a feedback network of relationships to build residential buildings of various elements. Residential building is a three-dimensional space with complex functions, with this new way of thinking to understand the object, it can better develop design ideas, form a more excellent design.

\section{B. To Form A Unique Perspective Interpretation of Theoretical Knowledge Divergent Design Thinking}

To discuss the theory of building from the unique perspective of an important means of formation of a new building concept, which allows us to restructure the building knowledge, to identify these pieces of knowledge may be combined into a new point of view, these new ideas may be immediacy conclusion, perhaps assuming that the form may be present, or that existing knowledge is an entirely different concept of variation, and therefore unique perspective interpretation could make the building of theoretical knowledge in the application there is room for greater innovation, enabling the designer to form a more unique variation design thinking, design thinking this will lead to different levels of the building designer elements interrelated, or there will be no associated object combined with each other to form the result of a mutation, resulting in a more unique innovations. This requires designers to have more insight, innovation can be found in the various elements of residential building space configuration, choose the right direction and scale innovative design.

\section{INNOVATIVE APPROACHES TO THE DESIGN OF RESIDENTIAL BUILDINGS}

Innovative approaches to building design is a scientific method, which is the main architectural design practice way through a series of controlled conditions to achieve the architectural innovation, pioneering architectural achievements arising from this practice often can be more effective in meeting people's needs, is scientific methodology embodied in the innovation of architectural design [3]. Faced with insufficient degree of innovation of contemporary residential building design issues, an urgent need in the explicit design goal of the premise of the theory of architecture, based on the introduction of new humanities and natural sciences to build advanced technology and residential building design innovation system, from fundamental solve the innovation and development of residential buildings, residential buildings designed to ensure constantly evolve and develop to meet growing customer needs.

\section{A. The Structure of Morphological Variation Constitution}

With the development of technological sciences, residential building design with more innovative means, its morphology and spatial patterns of variation as possible. Building exterior shape evolving aims to be more adapt to the external environment, architectural interior space form primarily to enable people to have a more comfortable living space, inside and outside of unity in order to achieve a more perfect harmony between man and nature and architectural unity of the three. In the form of variation is mainly divided into two kinds, one adaptive mutation surface morphology, surface variation of this form of innovation is mainly composed of a greater emphasis on adaptive structure. For example, in our building design, in order to better adapt to and protect the ecological environment, building structures and other means of weakening or cut in order to obtain morphological harmony. Second, form a protective mutation. Innovative approach to this form primarily to reduce interference and some special effects on the natural environment of the building, to find the balance point between architecture and the environment, to achieve complete unity of architectural value and natural environment. From a historical and contemporary value of social comparison, the social environment of new ideas and new theories will promote architectural design variations and extensions, so the architects have more new ideas and a new vision and new and innovative means. 


\section{B. Dynamic Optimization of Overall Structure}

Overall residential construction design innovation requires designers to large architectural perspective to reveal the characteristics and composition of the law, the relationship between the composition and function of the relationship between the various components of a comprehensive consideration of the building, but the conventional analysis is performed under a state of rest, which often cause The end result of the design and objectives have a certain gap, and this late stage error correction is difficult. We emphasize the dynamic optimization design, it is to grasp the changes and trends that may arise from the building as a whole, in order to consider a wide range of dynamic perspective after building the operating environment and spatial variability of expansion and other variables, which in fact is the requirement that we must Recognizing the building process from design to construction is a dynamic, integrated process differences, it must continue to optimize the relationship between the various parts of the building, from the perspective of a comprehensive analysis of the dynamic elements of its form, function, environment, applications, In the overall structure of the building in the use and future expansion always maintain an optimal state.

\section{Ecological Treatment of Building Materials}

Today the public's environmental awareness becomes more and more intense, increasing emphasis on the construction of residential buildings and blend the natural environment, emphasizing the concept of green. Under the guidance of this concept, design theory and method of residential buildings have undergone major changes. First of buildings to achieve ecological goals, it must be different from traditional building materials by building a processing means, to achieve ecological processing of building materials, building components to achieve environmental adaptability, requiring designers to handle more sophisticated materials, emphasizing the ecological building materials performance, positive natural ecology of the theoretical construct construction ecology; secondly focusing on environmental impact of building materials, construction materials to a more natural way to extend in the environment, nature and the environment to achieve integration of building components.

\section{Innovation of Energy-Saving Technologies}

Residential building energy consumption has become an important issue in the design, thereby reducing energy consumption to achieve economical operation mode, and create energy saving residential space has become the guiding ideology of architectural design. In the residential building design, we must take into account the application of advanced energy-saving technology, from the initial design stage, in the middle of the construction and operation of the latter part of the link, we must strive to ensure energy consumption. For example, in the design stage should consider how to ensure the construction of high efficiency, low energy consumption, and to choose what kind of energy-saving technologies in order to ensure the operation of the energy consumption of residential late and other issues, so try to choose advanced energy conservation technology structure of the building build. Such as the use of environmentally friendly composite materials to build the wall, use solar energy for temperature regulation of residential space, or the use of more advanced circulatory system, the construction of some of the substances generated during the operation were utilized to achieve recycling of energy, to reduce waste emissions, energy conservation purposes.

\section{CONCLUSION}

Issues article on residential building design innovation were discussed, specifically the role of multivariate factor in residential construction innovation. Innovative design of residential buildings on people living space planning creative process is innovative thinking, design innovation and manufacturing innovation process, in this process requires the designer to remain creative thinking, and imagination to explore a variety of assumptions, will the latest technological tools and technology and the new building theory, to seize the key issues of residential building design innovation, with specific ways of thinking to complete a variety of expression constructs residential space elements, creating a form of residential buildings have profound meaning.

\section{REFERENCES}

[1] Pan Haizhou. The architectural design of the multi dimensional thinking [J]. Central building, 2010 (7): 174-176.

[2] Liu Fang. Analysis of architectural design innovative thinking [J]. Chinese and foreign construction, 2010 (4): 66-67.

[3] Yu Wenping. Research on the architectural design innovation method [J]. Architectural design management, 2010 (1): 25-26. 